Massachusetts, USA. ${ }^{2}$ Thrasos Innovation Inc., Montreal, Quebec, Canada. ${ }^{3}$ Division of Cardiology, Department of Medicine, Massachusetts General Hospital/Harvard Medical School, Boston, Massachusetts, USA. ${ }^{4}$ Division of Nuclear Medicine, Department of Radiology, University of Massachusetts Medical College, Worcester, Massachusetts, USA. ${ }^{5}$ Department of Nephrology and Rheumatology, Goettingen University Medical Center, Georg August University, Goettingen, Germany. ${ }^{6}$ Harvard-Massachusetts Institute of Technology Division of Health Sciences and Technology, Boston, Massachusetts, USA. ${ }^{7}$ Department of Biological Chemistry and Molecular Pharmacology, Harvard Medical School, Boston, Massachusetts, USA. e-mail: rkalluri@mdanderson.org

1. Whitman, M.L. Nat. Med. 19, 809-810 (2013)

2. Sugimoto, H. et al. Nat. Med. 18, 396-404 (2012).

3. Kirsch, T., Sebald, W. \& Dreyer, M.K. Nat. Struct. Biol. 7, 492-496 (2000).
4. Allendorph, G.P., Vale, W.W. \& Choe, S. Proc. Natl. Acad. Sci. USA 103, 7643-7648 (2006).

5. Daopin, S., Piez, K.A., Ogawa, Y. \& Davies, D.R. Science 257, 369-373 (1992)

6. Schlunegger, M.P. \& Grutter, M.G. Nature 358, 430-434 (1992).

7. Griffith, D.L., Keck, P.C., Sampath, T.K., Rueger, D.C. \& Carlson, W.D. Proc. Natl. Acad. Sci. USA 93, 878-883 (1996).

8. Bosukonda, D. Screening method for bone marrow morphogenic mimetics. Patent application number: PCT/US00/42657. WIPO publication WO 2002/039118. (2002).

9. Duan, Z. et al. J. Huazhong Univ. Sci. Technolog. Med. Sci. 28, 426-430 (2008).

10. Lock, J. \& Liu, H. Int. J. Nanomedicine 6, 2769-2777 (2011).

11. Saito, A., Suzuki, Y., Ogata, S., Ohtsuki, C. \& Tanihara, M. J. Biomed. Mater. Res. A 72 77-82 (2005).

12. Chen, Y. \& Webster, T.J. J. Biomed Mater. Res. A 91, 296-304 (2009).

13. Weiner, H.L. J. Clin. Invest. 106, 935-937 (2000).

14. Amidon, G.L. \& Lee, H.J. Annu. Rev. Pharmacol. Toxicol. 34, 321-341 (1994).

15. Bosukonda, D., Shih, M.S., Sampath, K.T. \& Vukicevic, S. Kidney Int. 58, 1902-1911 (2000).

\title{
MSCs: science and trials
}

\section{To the Editor:}

The recent Perspective by Bianco et al. ${ }^{1}$ raised many important issues. However, the authors did not make it clear that mesenchymal stem cells (MSCs) from mice can be substantially different from MSCs from other organisms, ranging from rat to man, and they made no distinction of which results are from studies using human MSCs and which are from other species. Our work, in which we focused on human MSCs, used bone marrow as a source because it was thought to be a reservoir of, and renewable source for, these cells and did not require harvesting tissue in use'2. The study of human MSCs was pioneered by Caplan and co-workers ${ }^{3}$, and the research that preceded their efforts was in many different species, but not humans-this is nontrivial today, and it was nontrivial 20 years ago. Notably, akin to the admonitions of Bianco et al. ${ }^{1}$ and the data presented in Box 1 of their Perspective, the MSCs isolated by Caplan and co-workers had an in vivo assay as their origin ${ }^{3}$. However, at almost the same time as the cells became a band on a density gradient, hematologists recognized that this might be what was needed for patients with cancer to aid in the engraftment of transplanted hematopoietic progenitor cells ${ }^{4}$. Human stromal cells had been isolated a decade earlier for in vitro support of hematopoietic cells, but they were never of sufficient quality for clinical use, they had not been tested for multipotency and they were not pursued further ${ }^{5}$. In addition, given the requirement for selecting lots of fetal bovine serum by an in vivo assay, it is unlikely the early human stromal cells were indeed MSCs.

There are many examples in which new knowledge about stem cell therapy can only be learned by human testing and clinical trials. As was the case for hematopoietic stem cells in the 1970s and 1980s, the first in-man testing with human MSCs in the 1990s and 2000s has been invaluable. No prospective in vitro study or animal testing could provide the knowledge attained through actual human exposure. Compassionate use can also provide great insight, as in the case of a child with deadly grade IV graftversus-host disease who responded to the immune-modulating ability of MSCs not once but twice ${ }^{6}$. In regard to the much larger medical need of repairing cardiac damage, such as that caused by an infarct, meta-analyses of multiple studies have not detected safety issues ${ }^{7}$, and multiple studies have indicated improvement in the heart after treatment with MSCs. If the number of clinical trials conducted so far is any indication, many researchers remain positive about the clinical potential of MSCs for use in patients. Perhaps it is precisely because bone marrow MSCs have been so well studied in the last 20 years that we know enough about them to make them surprisingly useful.

The distinction between the skeletal stem cell described by Bianco et al. ${ }^{1}$ and what I would describe as an MSC is that the authors believe their skeletal stem cell is the only true MSC and must be defined in situ, whereas I and many others believe that MSCs (and other stem cells) are a product of their environment and this environment can exist or be developed in other locations, including the culture dish. The in vivo ossicle method described by Bianco et al. ${ }^{1}$ has not met with broad acceptance because it has little new to teach us about understanding MSCs and has little use to most researchers pursuing cellular therapeutics, as MSCs cannot be grown this way in large numbers. In their Perspective, Bianco et al. claim that an MSC is a cell with a "precisely defined physical and conceptual entity," and it cannot be known outside of its in situ context-that is their point ${ }^{1}$. The authors describe one of the in situ locations for the cell, but they do not describe a pure cell population; rather, they describe a location enriched in these cells, as originally shown by Haynesworth et al. $^{3}$ using the antibodies SH-2 and SH-3 (antibodies to CD105 and CD73, respectively). Our work in 1999 reported many surface markers on MSCs that represented how these cells interact with their neighbors and their environment and that can be used to 'prospectively' enrich for MSCs from tissue sources. Notably, Bianco et al. ${ }^{1}$ continue to promote STRO-1 as a marker of their skeletal stem cell, although this antibody was developed 20 years ago and undoubtedly recognizes one of the more than 300 known CD antigens.

There are more than 20,000 publications on MSCs, and perhaps half of them are largely confirmatory reports; thus the case for MSCs has been made stronger, not weaker, as more studies have been peer reviewed and published. However, there is an evident need to have scientific benchmarks and avoid 'drift', and to continue to disseminate solid findings in critical peer-reviewed journals. The abundant interest in this issue would quickly wane if there were not important findings continuing to be made in vitro and in vivo and if these findings did not hold broad medical promise.

COMPETING FINANCIAL INTERESTS

The author declares no competing financial interests.

\section{Mark F Pittenger}

Department of Surgery, University of Maryland School of Medicine,

Baltimore, Maryland, USA.

e-mail:m.pittenger@smail.umaryland.edu

1. Bianco, P. et al. Nat. Med. 19, 35-42 (2013).

2. Pittenger, M.F. et al. Science 284, 143-147 (1999).

3. Haynesworth, S.E., Goshima, J., Goldberg, V.M. \& Caplan, A.I. Bone 13, 81-88 (1992).

4. Lazarus, H.M. et al. Bone Marrow Transplant. 16, 557-564 (1995).

5. Castro-Malaspina, H. et al. Blood 56, 289-301 (1980).

6. Le Blanc, K. et al. Lancet 363, 1439-1441 (2004).

7. Lalu, M.M. et al. PLoS ONE 7, e47559 (2012). 